\title{
Erratum: ACF7 regulates inflammatory colitis and intestinal wound response by orchestrating tight junction dynamics
}

Yanlei Ma, Jiping Yue, Yao Zhang, Chenzhang Shi, Matt Odenwald, Wenguang G. Liang, Qing Wei, Ajay Goel, Xuewen Gou, Jamie Zhang, Shao-Yu Chen, Wei-Jen Tang, Jerrold R. Turner, Feng Yang, Hong Liang, Huanlong Qin \& Xiaoyang Wu

Nature Communications 8:15375 doi: 10.1038/ncomms15375 (2017); Published 25 May 2017; Updated 11 Jul 2017

The affiliation details for Yanlei Ma and Yao Zhang are incorrect in this Article. The correct affiliation details for these authors are given below:

Yanlei Ma:

Department of GI surgery, Shanghai Tenth People's Hospital Affiliated with Tongji University, 301 Yanchang Road, Shanghai 200072, China.

The University of Chicago, Ben May Department for Cancer Research, Chicago, Illinois 60637, USA.

Department of Colorectal Surgery, Fudan University Shanghai Cancer Center, Shanghai, China.

Yao Zhang:

State Key Laboratory Cultivation Base for the Chemistry and Molecular Engineering of Medicinal Resources, Ministry of Science and Technology of China, Guanxi Normal University, Guilin 541004, China.

(c) Open Access This article is licensed under a Creative Commons Attribution 4.0 International License, which permits use, sharing, adaptation, distribution and reproduction in any medium or format, as long as you give appropriate credit to the original author(s) and the source, provide a link to the Creative Commons license, and indicate if changes were made. The images or other third party material in this article are included in the article's Creative Commons license, unless indicated otherwise in a credit line to the material. If material is not included in the article's Creative Commons license and your intended use is not permitted by statutory regulation or exceeds the permitted use, you will need to obtain permission directly from the copyright holder. To view a copy of this license, visit http://creativecommons.org/licenses/by/4.0/

(C) The Author(s) 2017 